S. I. THE SON OF GOD

DOI: https://doi.org/10.14428/thl.v2i3.17663

\title{
The Two Natures of the Incarnate Christ and the Bearer Question
}

\author{
MIHRETU P. GUTA \\ Biola University E Azusa Pacific University \\ mihretu.p.guta@biola.edu
}

\begin{abstract}
The Chalcedonian Definition states that the incarnate Christ is both fully human and fully divine. But spelling out what the Chalcedonian Definition entails continues to be a subject of intense controversy among philosophers and theologians alike. One of these controversies concerns what I call the problem of the bearer question. At the heart of this question lies whether or not the two natures of Christ require two distinct bearers. In section I, I will explain the problem of the bearer question and how it arises directly due to the Chalcedonian Definition. In section II, I will propose a solution to the problem of the bearer question within the framework of what I call, a 'Multi-Track Disposition Model of the Incarnation'. At the heart of this model lies the notion that the manifestation of properties is multi-directional in the sense that there is a reciprocal partnership among property manifestations. In section III, I will contrast the solution proposed to the bearer question by the Multi-Track Model to that of a 'Kenotic Model of the Incarnation'. I will argue that the Multi-Track Model provides us with better conceptual resources to make sense of the bearer question. Finally, in section IV, I will briefly point out why ultimately a conclusive answer to the bearer question may still prove to be elusive because the bearer question gives rise to a host of other unresolved questions.
\end{abstract}

Key words: Bearer, Properties, Manifestations, Personhood, Incarnation

\section{Introduction}

At the heart of the Chalcedonian Definition (for brevity CD) lies the claim that the incarnate Christ is both fully human and fully divine. ${ }^{1}$ Spelling out what CD entails, however, continues to be a subject of controversy among philosophers and theologians. Whether or not there is a promising prospect to fully work through theological as well as philosophical complexities that arise in dealing

\footnotetext{
${ }^{1}$ For a fuller description of the Chalcedonian Definition (AD 451) see Noll $(2000,76)$ and Sanders (2007).
} 
with CD, a pro-Chalcedonian theorist cannot afford to compromise four nonnegotiable claims that are ontological kernels of CD: ${ }^{2}$

(1) Identity Thesis: The incarnate Logos is numerically one person.

(2) Nature(s) Thesis: The incarnate Logos is fully human and fully divine.

(3) Distinction Thesis: The incarnate Logos's human and divine natures are distinct.

(4) Unity Thesis: The incarnate Logos is a unifier of the human and the divine natures.

Individually taken, these theses enjoy some level of conceptual autonomy from each other in that the concepts are not univocal. At the most basic level, however, the four theses are interdependent and interrelated. In fact, an adequate grasp of (1) will be hard to come by without taking into account (2)(4). Similarly, making progress on (2) is contingent on whether or not we take into account (1), (3) and (4). Again dealing with (3) necessitates bringing to the table (1), (2) and (4). Last, but not the least, making progress on (4) requires direct engagement with (1) - (3). Taken together, as I shall argue, (1)-(4) can be shown to make a coherent whole as well as collectively underlie what I shall call the problem of the bearer question. At the heart of the problem of the bearer question lies figuring out whether or not the two natures of Christ require more than one bearer.

We can investigate this problem in at least three ways. The first way concerns the two bearers view. On this theory, the two natures of Christ can be said to have two distinct bearers. That is, one bearer for the human nature and another bearer for the divine nature. The second way concerns the one bearer view. On this theory, the two natures of Christ can be said to have a single bearer. The third way concerns the hybrid of the two bearers and the one bearer views. On the hybrid theory, there is a sense in which the two natures of Christ can be said to require two bearers and there is also another sense in which the two natures of Christ can be said to require one bearer. But the hybrid view does not make headlines in the literature. In this case, the one bearer view takes the driver's seat in dominating discussions besetting CD. Also as we shall see, the two bearer-view is unacceptable because it's unorthodox by virtue of Nestorian heresy. However, in this essay, I will attempt to show why the hybrid view should be taken seriously, since it does more comprehensive justice to the central claims of CD as indicated in (1)-(4). For reasons that will be explained

\footnotetext{
${ }^{2}$ In characterizing CD in this way, I am rejecting linguistic as well as metaphorical readings of $\mathrm{CD}$. In the case of the former, $\mathrm{CD}$ is said to be "linguistically regulatory" with no further ontological intent whereas in the case of the latter, the language of $\mathrm{CD}$ is said to be metaphorical in nature. For details on these and other readings of CD, see Coakley (2002).
} 
throughout this essay, I associate the two bearers view with the easy problem of the bearer question; the one bearer view with the hard problem of the bearer question and the hybrid view with the hardest problem of the bearer question, respectively. ${ }^{3}$ My primary focus in this essay will be on the hardest problem of the bearer question.

Of the four central claims that underlie the bearer question, as I will argue in this essay, (1) takes up the driver's seat in its metaphysical centrality. Not only does (1) set the tone for the problem of the bearer question as a whole, but it also imposes constraints on the sort of answers a proponent of CD proposes to (2)-(4). So in spelling out the ontology of the personhood of the incarnate Christ, our primary starting point must be (1). More importantly, a close examination of (1) sheds important theological as well as philosophical insights on the question of what actually can be said to have happened to the Logos, the second person of Trinity, at the incarnation. At the heart of the doctrine of the incarnation lies, "the belief that at a particular point in human history, a member of the Trinitarian God became, or took on, flesh and a genuine human existence in Jesus of Nazareth" (Holland 2012, 59; cf. Crisp 2016 and Webster 2004). The problem of the bearer question primarily consists in discerning the manner in which God assumed humanity.

The solution to the problem of the bearer question will finally emerge from what I call: a Multi-Track Disposition Model of the Incarnation. This is the model that attempts to spell out the incarnate Christ's divine and human natures within the framework of the contemporary metaphysics of dispositions or what is also known as a "powers ontology" (Heil 2012 and 2005, 343). A disposition is said to be a "capacity", "power", "potentiality", or "property" an object or substance possesses. ${ }^{4}$ Dispositions are said to manifest themselves in certain ways under different circumstances. For example, salt manifests solubility (i.e. a disposition) by dissolving if it is put in water. To avoid confusion, unless otherwise stated, in this article, I take the term 'disposition' to mean property. ${ }^{5}$ I use the phrase 'dispositional properties' when I talk about properties associated with the incarnate Christ. I will argue that for compelling philosophical as well as theological reasons, adopting a Multi-Track Disposition Model of the Incarnation proves to be much preferable to solving the problem of the bearer question to that of a Kenotic Model of the Incarnation.

\footnotetext{
3 The phrases 'easy problem' and 'hard problem' are taken from David Chalmers's famous theory of the problem of consciousness, see Chalmers (1996) and (2010).

4 Some philosophers distinguish between the notion of "disposition" and the notion of "power", see Bird (2013). But following Heil, I use these notions interchangeably, see Heil (2005).

5 Taking dispositions as properties could be disputed but there are excellent reasons for taking them as such, see Vetter (2015) and Mumford (1998).
} 
Unlike a Kenotic Model of the Incarnation, a Multi-Track Disposition Model of the Incarnation has better conceptual resources to satisfy the metaphysical questions we confront regarding the personhood of the incarnate Christ. I conclude this article by claiming that, ultimately a conclusive answer to the problem of the bearer question may still prove to be elusive because the bearer question gives rise to a host of other unresolved questions.

\section{The Problem}

Above I classified the theories we use to investigate the problem of the bearer question into three domains, namely: the easy, the hard and the hardest. Yet these domains are not entirely independent of each other. In fact, the easy problem of the bearer question is said to be easy only relative to the hard problem of the bearer question and similarly, the hard problem of the bearer question is said to be hard relative to the easy problem of the bearer question. Again, the hardest problem of the bearer question is said to be hardest relative to both the hard and the easy problems of the bearer questions. Taken this way, these three categories of the problem of the bearer question can be said to be quasi-interdefinable. Each domain poses different levels of difficulties to a proChalcedonian theorist.

\subsection{The Easy Problem}

Central to the easy problem of the bearer question is figuring out whether or not the incarnate Christ's human and divine natures each independently necessitate two distinct bearers. That is, a human bearer for the human nature and a divine bearer for the divine nature. More precisely, the easy problem of the bearer question asks whether Jesus of Nazareth is the bearer of the human nature whereas the Logos is the bearer of the divine nature. Put this way, the easy problem of the bearer question is comprised of two propositions:

P1: Jesus of Nazareth is the bearer of the human nature.

P2: The Logos is the bearer of the divine nature.

It could be said that, individually considered, there is nothing wrong with P1 and P2. For example, as they stand, P1 and P2 do not give rise to a notoriously difficult predicate attribution problem, which as we shall see, is the case in relation to the one bearer theory. The main issue that should concern a defender of P1 and P2 would be spelling out the nature of unity that can be said to exist between Jesus of Nazareth and the Logos. But the devil is in the details. 
Whether individually or collectively taken, P1 and P2 raise a biblical/theological red flag for a pro-Chalcedonian theorist. The biblical/theological red flag I have in mind can be summed up as follows. That is, individually considered, P1 and P2 can go their own separate ways. In this case, for example, the predicate of P1, "...the bearer of the human nature" is not predicated of the subject of P2 and similarly, the predicate of $\mathrm{P} 2$, "...the bearer of the divine nature" is not predicated of the subject of P1. But understood this way, P1 and P2 turn out to be in serious conflict with (1) thereby violating CD. Recall that (1) is the identity thesis according to which the incarnate Logos is numerically one person. Against (1), collectively considered, that is, the conjunction of P1 and P2, multiplies entities beyond necessity. That is, P1 and P2 refer to two distinct bearers. We can put this point as follows:

P3: Jesus of Nazareth is the bearer of the human nature and the Logos is the bearer of the divine nature.

But in light of (1), which is one of the central claims of CD, P3 would not be acceptable. This is precisely because P3 implies Nestorianism, the view that assumes two persons in the incarnate Christ, namely human and divine. If Nestorianism is true, then it follows that there are two independent souls, wills and centers of consciousness in the incarnate Logos. But Chalcedon unequivocally rules out such an ontology of the personhood of Christ. So for a pro-Chalcedonian theorist P3 does not seem to pose a serious theological threat and thus, it can be considered to be an easy problem to deal with. This is because the case against one of the early Christological heresies, Nestorianism (which P3 entails) is now a settled matter. But settled on what grounds? Here following James Arcadi, we can say that the grounds involve scripture, creeds and the teachings of the church. As Arcadi remarks:

When thinkers past and present reflect on the data provided in these starting
points [i.e., scripture, creeds or other authoritative teachings of the Christian
Church], by and large they have come to the conclusion that Christianity teaches
that Jesus Christ is both God and a human being. Those following the creedal
material of the Nicene Creed and "Definition" of Chalcedon take it that Jesus
Christ is one person-the second person of the Trinity - with two natures, the
divine nature and an instance of human nature (Arcadi 2018,1).

\subsection{The Hard Problem}

Given that P3 is rejected, for some of the reasons given above, the bearer question should be modified. In its modified version, the problem of the bearer question boils down to making sense of (2) the nature thesis in relation to (1) the 
identity thesis. Recall that (2) states that the incarnate Logos is fully human and fully man. (1) States that the incarnate Logos is numerically one person, i.e. the God-man. To see where the hard problem of the bearer question lies in (1) and (2), they have to be merged together, in which case P3 should be modified as P3*:

P3*: The incarnate Logos/Jesus Christ is the bearer of both the human nature and the divine nature.

Compared to P1, P2 and P3, the advantage of P3* consists in avoiding the separation problem of P1 and P2 on the one hand and the duplication/multiplying problem of P3 on the other hand. The sense in which $\mathrm{P}^{*}$ avoids both of these problems is by merging the subject of $\mathrm{P} 1$, that is, Jesus Christ with the subject of P2, that is, the Divine Logos. In doing so, P3* also unifies the predicates of both P1 and P2 under one umbrella or subject (Jesus Christ/Divine Logos). In this case, $\mathrm{P}^{*}$ satisfies (4) the unity thesis according to which the incarnate Logos is a unifier of the human and the divine natures. The sense in which $\mathrm{P}^{*}$ satisfies (4) consists in an ontologically rooted co-existence of the two natures of Christ in a single bearer. Moreover, P3* satisfies (3) the distinction thesis which states that the incarnate Logos's human and divine natures are distinct. The sense in which $\mathrm{P}^{*}$ satisfies (3) consists in an ontologically rooted real as opposed to mere conceptual distinction that holds between the two natures of Christ exemplified by a single bearer.

What emerges from $\mathrm{P3}^{*}$ is the notion that makes the heart of $\mathrm{CD}$. That is, a single person, Jesus Christ is both a human being and a divine being. In his essay entitled, "Recent Developments in Analytic Christology" (also quoted earlier), Arcadi points out that over the past four decades, the notion that a single person, Jesus Christ has both divine and human natures produced an immense amount of discussion (2018). One of the major concerns in these discussions has to do with the coherence of attributing divine and human attributes to a single person as indicated by P3*. Timothy Pawl claims that the incoherence associated with $\mathrm{P}^{*}$, which he describes as a "fundamental problem", arises due to incompatible predications taken to be true of a single person, the God-man Jesus Christ. Some of the incompatible predicates Pawl discusses include, "passible" and "impassible". Attributing these sorts of incompatible predicates to a single person, Jesus Christ is said to result in contradiction (Pawl 2015, 86-88). Pawl responds to this charge within the framework of what he calls Conciliar Christology. At the heart of Conciliar Christology is the claim that the incarnate Christ is divine and human. Pawl's main goal in developing his Conciliar Christology is to look for a solution to the 'incompatible predicates' charge raised against the person of Christ. After 
discussing various proposed solutions, Pawl draws his own conclusion by arguing why the alleged incompatible predicates are not incompatible when said of the same thing. But here I cannot get into the details of Pawl's extensive discussions (Pawl 2015, 102-103; see also Pawl 2014 and 2016).

Unlike Pawl's approach which seems to be primarily linguistic in its orientation, Thomas Senor characterises the objection levelled against propositions like $\mathrm{P}^{*}$ as being metaphysical in nature. As Senor puts it:

To be fully divine is to meet all of those conditions necessary for divinity. Such a person will then be omnipotent and omniscient. To be fully human, on the other hand, requires a person to be limited in power and knowledge. So a person who is fully divine and fully human will be an omnipotent, omniscient being who is limited in power and knowledge. But that is a logically inconsistent description. Therefore, the doctrine of the incarnation is not even possibly true: it represents a metaphysical impossibility $(2007,558)$.

Although this objection is being framed from a metaphysical standpoint, Senor's subsequent analysis of it is more drawn towards making sense of whether or not the logical inconsistency objection holds up. Senor formulates the objection in six steps and describes it as the "inconsistent argument" (Ibid. 558). At the heart of the inconsistent argument is the assertion that Jesus Christ is fully divine and fully human. It is also said that Christ is an omnipotent and omniscient being. Yet, the same person, Christ is also said to be limited in power and knowledge. But how can this be? Senor discusses well-known responses proposed by kenotic theorists, Morris's 'two minds' theory and the compositional model theorists to the inconsistence argument. He takes the responses to be inconclusive. Pawl's and Senor's focus on the logical consistency aspect of $\mathrm{P}^{*}$ can be better understood as being attempts at resolving the hard problem of the bearer question. This must be the case because as we shall see, there is the hardest problem of the bearer question. If I am right about this, then in solving or at least in trying to solve the logical consistency problem, we can only say that we are focusing on one of the difficulties we face in dealing with $\mathrm{P}^{*}$.

\subsection{The Hardest Problem}

$\mathrm{P}^{*}$ is susceptible to blurring the ontological distinction between Jesus Christ and the Logos. In doing so, $\mathrm{P}^{*}$ also blurs the sense in which the predicates of P1 and P2 are united under one subject (Jesus Christ/Divine Logos). Such a blurring problem could get even worse if P3* is taken to imply a metaphysical identity in the sense that Jesus of Nazareth being strictly (i.e., numerically) identical with the Logos. To see this, we need to understand that, in his pre- 
incarnate state, the second person of the Trinity, the Logos, had no contact with physical matter. That is, until the time of the incarnation, the Logos did not experience embodiment. In this case, the greatest mystery of the incarnation lies in how it was possible for the Logos to become an embodied being.

While we may never know the details involving the Logos' becoming an embodied being, we can still raise questions as to what happened at the incarnation. These questions underlie what I earlier called a hybrid view. At the heart of the hybrid view lies the claim that there is a sense in which the two natures of Christ can be said to require two bearers and there is also another sense in which the two natures of Christ can be said to be true of one bearer. In this case, the essentials of the hybrid view emerge from the analysis of the interrelation that exists between the following three questions: $(A)$ is the incarnate Logos a physical being?; (B) is the incarnate Logos a purely immaterial being?; and (C) how does the incarnate Logos relate to the body of Jesus? If the incarnate Logos is a physical being, then He can be said to be a bearer of all physical properties that are necessary and sufficient for physicality. If the incarnate Logos is a purely immaterial being, then He can be said to be a bearer of all non-physical properties that are necessary and sufficient for immateriality. Here what we want to know is if there can be a sense in which two distinct bearers, in this case, a bearer of physical properties on the one hand and a bearer of non-physical properties can make up a single person. If this is possible, then a good case can be made to show that numerically distinct properties do not necessitate numerically distinct bearers thereby insulating the hybrid view potentially from being associated with Nestorianism.

Although by no means perfect, an analogy can be drawn from human ontology to flesh out the concept of a "single bearer-two bearers" hybrid view. Suppose that a human being is a purely material being. In that case, some nonreductive physicalist theories claim that despite being a purely physical being, a human person is a bearer of two distinct properties, namely: physical properties such as the firing of neurons in the brain and mental properties such as desire, beliefs and intentions (see Murphy and Brown 2007, 1-3 and 7-9). Here one of the significant problems defenders of this view face, inter alia, is showing how a physical system such as the brain can be said to be a bearer of non-physical properties. No conclusive philosophical or scientific solution is in sight in resolving this issue yet (see Kim 2006, 290-305; Chalmers 1996 and 2010).

But at the least, defenders of this view do not see a problem with a notion of "one bearer-two distinct properties". By contrast, suppose that a human person is a material-immaterial complex. In this case, some non-Cartesian substance dualists like E. J. Lowe argue that a human person does not appear to be identifiable with his or her organic body nor with any part of it, such as the brain. Lowe argues that a human person is physically embodied and even can 
be a "physical thing" in the sense of possessing physical characteristics. But Lowe argues that since different identity conditions apply to a human person and an organic body which embodies it, they are ontologically distinct. On Lowe's version of substance dualism, there are two distinct bearers of two distinct properties in a single embodied human being (see Lowe 2008, chaps. 1 and 5; cf. Guta 2011, 35-58). On Lowe's human ontology, there is a sense in which we can think of two distinct bearers of two distinct properties, namely a material body or part of it such as the brain on the one hand and a non-physical human person on the other hand. But here we do not want to say that every time we see a particular human person, say Mihretu, we are seeing more than one person. That would be highly counterintuitive. A common-sense conception of ourselves is that we are unified human persons. So there is a sense in which it can be said that there is one unified, embodied human person - a bearer of mental and physical properties. But within such unity it is also the case that there are two distinct bearers for mental and physical properties respectively.

Unlike the non-reductive physicalist theories, Lowe's dualist view nicely illustrates and captures the spirit of the hybrid view, i.e., the notion of "a single bearer-two bearers". But how does the hybrid view apply to the ontology of the personhood of Christ? To answer this question, first we need to establish some facts regarding the incarnate Logos's relation to the body of Jesus of Nazareth. In this case, the hardest problem of the bearer question single handedly consists in figuring out the nature of the relationship between Jesus and the Logos. But here we should guard against making two interrelated mistakes. These are: over-emphasizing the divinity of Christ over His humanity on the one hand and over-emphasizing the humanity of Christ over His divinity on the other hand. The former gives rise to what I call the divinity favoring problem whereas the latter gives rise to the humanity favoring problem. Yet, not every proChalcedonian theorists see this issue in the way it is being suggested here. As we shall see in section III, some pro-Chalcedonian theorists seem to worry a lot about preserving the humanity of Christ. This sort of problem is related to the sort of worries considered in our examination of P3*. To see this again, we need to modify $\mathrm{P}^{*}$ as $\mathrm{P}^{* *}$.

P3**: The Logos is Jesus Christ.

We must begin our examination of $\mathrm{P}^{* *}$ by disambiguating the sense of the auxiliary verb 'is'. Since the time of Aristotle, analytic philosophers distinguish between, at least, four distinct senses of 'is'. First, the 'is' of attribution, as in 'Plato is wise'. Second, the 'is' of identity, as in 'Water is $\mathrm{H}_{2} \mathrm{O}$ '. Third, the 'is' of instantiation, as in 'A human being is a mammal'. Fourth, the 'is' of 
constitution, as in 'A human brain is a collection of nerve cells' (see Lowe 2009, 3-4). Of these four senses of 'is', what is implicated in P3 ${ }^{* *}$ is, the 'is' of identity. Depending on the sort of conclusion one infers based on the 'is' of identity in $\mathrm{P}^{* *}$, important theological as well as metaphysical questions could emerge. For example, given $\mathrm{P}^{* *}$, does strict (i.e., numerical) identity hold between the Logos and Jesus Christ? If so, as Arcadi points out, for some defenders of "transformationalist model of the incarnation", such a strict identity relation between the Logos and Jesus means that at the incarnation, the Logos transformed into a human (Arcadi 2018, 4-5). For example, within the framework of his physicalist ontology, Trenton Merricks claims, "God the Son in the incarnation is identical with the body of Jesus. That is, in becoming human, he became a body" $(2007,294)$.

But in light of the hybrid view defended in this essay, any attempt that tends to favour divinity over humanity or vice versa in the person of Christ turns out to be unacceptable. In this case, we will have to reconceive the bearer question and if we do so, then the incarnate Logos can be said to be the single bearer of the two distinct natures, human and divine. But the bearer question as reconceived here needs more unpacking. In this case, our focus should be on spelling out the sort of unity that exists between the Logos and Jesus of Nazareth. We also need to show in what sense the Logos can be said to be genuinely human without thereby forfeiting any of His pre-incarnate ontological nature and identity. In this case, we can modify $\mathrm{P}^{* *}$ as $\mathrm{P} 3^{* * *}$ :

P3***: The Logos is an embodied being.

Unlike the other formulations examined so far, $\mathrm{P} 3^{* * *}$ avoids both the divine favoring and the human favoring problems. We can also see that given $\mathrm{P}^{* * *}$, it is the human Jesus Christ's body that the Logos assumed in becoming incarnate. Sometimes it is said that the incarnate Logos cannot experience human limitations and also maintain at the same time all of His divine attributes for that would lead to logical incoherence. But the incoherence charge is misplaced (see Morris 1986, 9-24). Kenosis theorists also claim that certain divine properties must be rendered temporarily inoperative to make room for the human nature. For reasons we shall see, I find such arguments to be highly unpersuasive. For now, I suggest two ways to make sense of the hardest problem of the bearer question in light of $\mathrm{P}^{* * *}$. Both of these ways attempt to shed some light on the nature of the ontological unity between the Logos and Jesus.

First, following John Webster, I too think that adopting the language of anhypostasis and enhypostasis, gives us an excellent conceptual framework to make sense of the Logos's becoming flesh. These concepts, as Webster points out, show two things. First, the man Jesus has no personal center of subsistence, 
i.e., hypostasis in and of himself. Hence, the man Jesus is said to be "anhypostatic". Secondly, the man Jesus's hypostasis is "in" the Logos which assumes flesh. That means that the human nature of the man Jesus is said to be "enhypostatic" or dependent on the Logos (Webster 2004, 218; cf. Crisp 2007, Chap. 3). Second, along similar lines, Anna Marmodoro and Jonathan Hill defend the model of incarnation that allows for an existential dependence between the Logos and Jesus. As Marmodoro and Hill remark:

Existential dependence allows one to distinguish the two property bearers in Christ...But at the same time it gives a relation between these two bearers which is strong enough to account for a genuine unity between them....Existential dependence-embedded in a model in which Jesus comes into being only at the moment of union-appears to deliver the most promising metaphysics of the incarnation... (Marmodoro and Hill 2008, 124).

Marmodoro and Hill's, as well as Webster's remarks as briefly stated above might open a door for an objection. For example, it could be said that given that the human Jesus Christ is ontologically dependent on the Logos as discussed above, it would follow that such Christology suffers from divinity favoring problem and humanity understating problem. If this objection has merit, then it should be of a serious concern for a pro-Chalcedonian theorist. This is because favouring divinity over humanity or vice versa in the person of Christ would be incompatible as Marmodoro and Hill correctly observed with "the soteriological principle that, for salvation to happen, humanity and divinity must have met in a genuine unity" $(2008,99)$.

However, I do not think that the objection considered here succeeds. For one thing, the objection in this case reverses the order of what is being stated in $\mathrm{P}^{* * *}$. The primary issue in $\mathrm{P}^{* * *}$ is to figure out how divinity united with humanity as opposed to the other way around. If so, what $\mathrm{P} 3^{* * *}$ requires from us is to provide a framework within which we can make sense of the coequal existence of the divine and human natures in a single embodied bearer. It seems then perfectly plausible to say that Jesus of Nazareth is the bearer of the human nature and the Logos is the bearer of the divine nature yet the deep intrinsic unity that obtains between Jesus and the Logos make up a single unified person. So there is a sense in which there are two bearers of distinct properties in the incarnate Christ and yet there is another sense in which it can also be said that there is one bearer of divine and human natures, that is, the one God-man. Such analysis is what the hybrid view attempts to capture.

Given that P3*** presents the Logos as an embodied being, it nicely captures the spirit of (1) that is, the identity thesis in the sense of bringing humanity and divinity to converge on a single bearer. But how do the central claims of the 
hybrid view apply in the case of the incarnate Logos? How would the manifestations of the divine and the human natures of the incarnate Logos play out in a single bearer? These are extremely important questions that need to be properly addressed if we are to have any meaningful progress in our handling of the hardest problem of the bearer question. In the next section I take up that discussion within the framework of the "Multi-Track Disposition Model of Incarnation". ${ }^{6}$

\section{Multi-Track Disposition Model of the Incarnation}

In the first part of this section, I will briefly explain what the notion of a multitrack disposition is. In the second part, I will use the metaphysics of dispositions discussed in the first section to develop the multi-track disposition model of the incarnation and show how the model sheds some light on the hardest problem of the bearer question which this essay focuses on.

\subsection{Dispositions}

What are dispositions? Commonly understood, dispositions are taken to be properties that can be ascribed to things. Stephen Mumford distinguishes three classes of such things, namely objects, substances and persons (Mumford 1998, 3; cf. Guta 2016, 4-11). We say that a glass is fragile or a person is irascible or sugar is soluble. Unlike categorical properties, ${ }^{7}$ dispositional properties are said to be distinguished by their manifestations. But the manifestation of dispositional properties are contingent on the presence of the relevant circumstances that give rise to them. For example, a fragile glass may not break, say if it is not dropped on the floor. Yet 'fragility' is said to be present in the glass. Again an irascible person may not express anger, say if he or she is not provoked yet still has irascibility. As Barbara Vetter points out, in making such dispositional claims, we are not primarily saying something about what fragile things such as the glass, or irascible person or soluble sugar is actually doing. Rather we are implying what such things would or could do. Understood this way, dispositions are said to be modal properties, linking them to possibility (Vetter 2015, 33ff). In light of such observations, a preliminary characterization

6 For contemporary discussions on the metaphysics of disposition, see Vetter (2015), Mumford (1998) and Heil (2012). Here I also draw upon my 'multi-track dispositions' view as it relates to human ontology, see Guta (2016).

7 Philosophers disagree over what categorical properties are and whether or not they even exist. Mumford uses "a crystalline structure of the glass or pottery" as example to illustrate categorical property, Mumford (2013). But nothing I have to say here hinges on these controversies. 
of the concept of dispositions takes the following form: "A disposition is individuated by the pair of its stimulus condition and its manifestation...: it is a disposition to M when S" (Vetter 2015, 34). The details in spelling out this sort of characterization of dispositions are often marked by complicated analyses involving conditionals. For example, Vetter expresses the simple conditional analysis of fragility as follows (Vetter 2013, 330):

(SCA) $X$ is fragile iff, if $X$ were struck, $X$ would break.

Here ' $X$ ' stands for a certain object, say a glass. The term 'struck' refers to the stimulus condition and the term 'break' stands for the manifestation. If, in this case, the stimulus condition is satisfied, that is, something strikes a glass then the breaking of a glass (i.e. its manifestation) follows. So, as it stands, SCA can be said to be true of our experiences of fragile things. We readily believe and in fact, take it for granted that, if we strike or drop fragile things, then we expect them to shatter or break. Although this is generally true, as we shall see, there are cases where even when the stimulus condition is satisfied, the relevant manifestation may not ensue. So there are counterexamples against SCA.

\subsection{What Are Multi-Track Dispositions?}

Now that we have some grasp of what the notion of a disposition amounts to, it is time to talk about multi-track dispositions. Originally, the term 'multi-track' was coined by Gilbert Ryle (1963, 114). The adjective 'multi-track' refers to the many ways by which the manifestation of dispositions takes place. In this case, multi-track dispositions are said to be individuated by several pairs of their stimulus conditions and their manifestations (Vetter 2015, 34). That is to say that multi-track dispositions have more than one kind of stimulus condition or manifestation, or both (Bird 2007, 21). Understood this way, multi-track dispositions are contrasted with single-track dispositions. In this case, Vetter characterizes a single-track disposition as follows:

(ST) Where $\mathrm{D}$ is a disposition and $\mathrm{C}$ a conditional of the form: if $\mathrm{x}$ were $\mathrm{S}$, then $\mathrm{x}$ would be $\mathrm{M}, \mathrm{D}$ is adequately characterized by $\mathrm{C}$ (and $\mathrm{C}$ alone) only if:

(a) For all objects $x$ that have $D$, if $x$ were $S$, then ceteris paribus $x$ would be $M$.

(b) For all objects $x$ that have $D$, if $x$ manifests $D$ at $t$, then $x$ is $M$ at $t$ and $x$ is $S$ at or before t. (Vetter 2013, 334)

Vetter's point is that to establish a single-track disposition, say a particular fragility of a glass with its corresponding particular manifestation (shattering), we need to show that (a) and (b) are satisfied. As they stand, (a) and (b) are not 
controversial. Given (a), if a certain object with certain disposition is stimulated, provided that something does not stand in its way that blocks its manifestation, then the relevant disposition will be manifested. Also as Vetter points out, given (b), if a disposition is characterized by a single conditional, we should expect to see it being characterized by a single pair of stimulus condition and manifestation. Furthermore, Vetter claims that "if the disposition is so characterized, it is only manifested in yielding the manifestation upon being subjected to the stimulus condition" (Vetter 2013, 334-335). Although (a) and (b) as briefly explained here may appear to be easily satisfiable within the framework of a single-track disposition, further reflections reveal serious problems with it. In this case, details aside, Vetter raises two problems each of which have to do with stimulus conditions. The first problem concerns qualitative diversity of the stimulus conditions. As Vetter puts it:

It is easy to see that most of our everyday dispositions are multi-track. A fragile glass may manifest its fragility in breaking upon being hit with a spoon, being dropped onto the floor, being sung to by a soprano, or being subjected to pressure over a period of time....Irascible people may manifest their irascibility by becoming angry upon being yelled at, being politely told to wait, or being disagreed with...what we have here are qualitatively different stimulus conditions, and accordingly several different conditionals: $x$ would break if it were dropped onto the floor, $x$ would break if it were touched, $x$ would break if it were sung to by a soprano, and so forth $(2013,335)$.

The second problem concerns the quantitative diversity of the stimulus conditions. In this case, Vetter remarks:

Not only dispositions, but also their typical stimulus conditions come in degrees. A glass can be struck with a greater or lesser force, a vase can be dropped from a greater or lesser height, a person can be yelled at more or less loudly. These properties are quantities: determinable properties with a range of determinates ordered by a relation such as that of being greater than $(2013,337-$ 338).

In light of both the qualitative and the quantitative diversities of the stimulus conditions, a single-track disposition view cannot satisfy the two conditions above in (a) and (b). Ironically, as Vetter argues, (a) and (b) rather end up implying multi-track dispositions. This result has direct bearing on the nature of the manifestation of dispositions as well. The remainder of our discussion will focus on that.

According to C. B. Martin, a particular disposition exists or it does not. That means that there is no necessary requirement for dispositions to manifest 
themselves. Martin claims that any unmanifesting disposition can be said to straight-out exist. For Martin, the lack of manifestation of a certain disposition at any given specific time or at any other time does not show their nonexistence (Martin 2008, 1-2; cf. 1994). As Martin remarks:

It is the unmanifested manifestation, not the disposition itself, that is the wouldbe-if or would-have-been-if, if anything is. There can be a disposition $A$ for the manifestation of acquiring a further disposition $B$ and, of course, disposition $B$ need not itself have any manifestation, but disposition $B$ can still be unfulfilled terminus of that for which $A$ has a specific directedness $(2008,2)$.

From Martin's remarks, we can extract, at least, two critically important points with respect to the nature of dispositions. First, the absence of the manifestation of certain dispositions does not in any way show that they do not exist. Second, if for whatever reason(s), dispositions are not manifested, then they can be taken as unmanifested manifestations. Consider some philosophers' favorite example, a china cup. It has certain dispositions. That is, the disposition to shatter if struck. Here the verb 'struck' stands for what is taken to be a stimulus condition and 'shatter' stands for what is understood to be a manifestation. So the question remains: will it be the case that every time a stimulus condition is met, that we should necessarily expect to see a manifestation of a certain disposition? In other words, should we expect to see a china cup shatter when struck? Under normal circumstances, the answer for such questions could be affirmative. In this case, for example, the SCA (the simple conditional analysis) we saw earlier can be said to be true. But there is a catch.

Suppose again a slightly modified scenario whereby a china cup is covered with an extremely thick blanket with multiple layers, such that when struck, the thick blanket completely absorbs the forceful impact-blocking it from reaching the china cup. In this case, the china cup remains un-shattered. Such is one way to understand Martin's phrase the "unmanifested manifestation." In this case, SCA fails. But is there any other sense in which the unmanifested manifestations themselves can be taken to be the actual manifestations of a different kind?

To help us properly understand the question raised above, I introduce the notion of "stimulus-response relation". Suppose a car A hits another car B and makes a dent on B. Here it could be said that A's impact was a reason for the dent appeared on B. In this case, B was just a passive recipient of A's action. Alternatively, it could also be said that as much as A was responsible in making a dent on B, B also was responsible in contributing to the dent on itself by entering into mutual causal activity with $A$. This is because, when A hits B, B responded to $\mathrm{A}$ by being hit by $\mathrm{A}$. So the interaction between $\mathrm{A}$ and $\mathrm{B}$ is a two 
way street (or multiple ways street) interaction as opposed to being a one way street. I argue that the latter way reflects the right kind of analysis of the scenarios envisioned between $\mathrm{A}$ and $\mathrm{B}$ and by extension any other similar scenarios as well. In light of this, the "stimulus-response relation", gives us deeply inadequate explanation(s) regarding the manifestation(s) of various sorts of dispositions. So we have good reasons for rejecting a rigid "stimulusresponse" mechanism. Once this is out of the way, whether or not the unmanifested manifestations themselves can be taken as the actual manifestations of a different kind turns out to be a defensible notion. Here the notion of reciprocal partnership among different dispositions is a good case in point.

For example, as Heil $(2012,120-130)^{8}$ argues, if we take a ball's sphericity, we can see that it endows it with a disposition to roll. Heil claims that it is in virtue of being spherical that the ball has: the disposition to make a concave, circular impression in a cushion; the disposition to reflect light thereby looking spherical; and the disposition to feel spherical when we touch it. In light of this, Heil claims that talk of single and multi-track dispositions is deeply mistaken from the beginning. Heil claims that dispositions quite generally are multitrack. Hence, dispositions would manifest themselves differently with different reciprocal partners $(2012,21)$. Here Heil is echoing Martin's two points we saw earlier concerning the nature of dispositions. Martin is an ardent defender of multi-track dispositions. Taken this way, dispositions have many reciprocal partners. That means that negative interfering factors such as absences, preventers, antidotes, blockers, inhibitors, etc., will no longer be taken as stopping a certain disposition from being manifested. This is because such things themselves are dispositions manifesting themselves with various reciprocal partners (Heil 2012, 126-130). As Heil remarks:

What of scurvy and the lack of vitamin C? A living body's healthy condition is a mutual manifestation of myriad finely tuned reciprocal disposition partners. When one of these is missing, you have a different sort of manifestation, just as you have a different sort of manifestation when you remove one of the cards from a pair of propped-up playing cards...An absence is not an entity, not something with properties providing it with distinctive powers. But certain kinds of manifestation require appropriately propertied somethings as reciprocal partners. When these are missing, the result is a different kind of manifestation $(2012,127)$.

${ }^{8}$ I use the term 'disposition' where Heil uses, the term 'power'. On mental dispositions, see Owen (2018). 
Here Heil's point is that if we embrace a multi-track disposition model, we understand that the manifestation of dispositions is not a one way-street as in, say one thing causing another in a linear fashion. By contrast, the manifestation of dispositions is the result of causings. By 'causings,' Heil is referring to mutual manifestings of various reciprocal partners $(2012,120)$. In this case, Heil's account of the manifestation of dispositions adds more clarity to Martin's earlier remarks. That is, rather than talking about unmanifested manifestation, now we can talk about manifestations tout court. The manifestation of dispositions is multi-faceted in that the apparent absence of the manifestation of certain dispositions does not show that no manifestation is taking place. Rather it only means that a different kind of manifestation is happening. So where does all these leave us?

The multi-track dispositions view as briefly presented above can be applied to shed some light on the doctrine of the incarnation. In the next section, I will be sketching out what I earlier called the multi-track disposition model of the incarnation. My goal is to show how this model provides us with some insights in dealing with the hardest problem of the bearer question.

\subsection{Multi-Track Disposition Model of the Incarnation}

The multi-track disposition model of the incarnation (MDMI, for short), takes the following two claims to be unqualifiedly true: (i) at the incarnation, the Logos's divinity was not diminished in any sense or form; and (ii) at the incarnation, the Logos experienced genuine humanity in the person of Jesus of Nazareth. Whether or not other models of incarnation take (i) and (ii) with some form of qualification is an open question (see Arcadi 2018, 4-7). But MDMI rejects introducing any qualifications into (i) and (ii). So MDMI embraces (i) and (ii) at face value and tries to understand how they can both be true. Understood this way, (i) and (ii) put constraints on MDMI.

(i) and (ii) are restatements of (1) the identity thesis central to CD. Whether taken in the case of the hard problem of the bearer question or the hardest problem of the bearer question, at the heart of (1) lies the following question: how could the divine and the human natures co-exist in perfect synergy in a single person? In addressing this question, much emphasis has been given to addressing the logical coherence of ascribing two seemingly incompatible attributes to a single person of Christ. This is the hard problem of the bearer question. But I also argued that there is the hardest problem of the bearer question. As shown in section I, the hardest problem of the bearer question is primarily ontological in nature. It attempts to make sense of the Logos's relation to Jesus of Nazareth without violating (1). 
We also looked at why the notion of "a single bearer-two bearers" proposal is defensible without violating the four theses that make up CD. But as indicated in the introduction of this essay, (1) enjoys metaphysical centrality. In this case, (2) the nature thesis, (3) the distinction thesis and (4) the unity thesis are all grounded in (1). So within the framework of the hybrid view introduced and defended so far, there are still lingering issues waiting to be resolved. In this case, the issue boils down to making sense of the two natures of the incarnate Logos in light of "a single bearer-two bearers" scenario. So how does MDMI help us in this case?

According to MDMI, the two natures of the incarnate Logos are dispositional properties. An example of divine dispositional properties include omniscience, omnipotence and omnipresence and the like. An example of human dispositional properties include limitations in knowledge, dependence on God, experiencing fear, feeling hungry, feeling thirsty and the like. These are dispositional properties because they are properties that the incarnate Logos manifests.

Earlier in the context of our discussion of the metaphysics of dispositions, we made a distinction between a single-track disposition and a multi-track disposition. It is said that in the case of a single-track disposition, the manifestation of any given disposition consists in a single stimulus condition and its corresponding manifestation.

Suppose that the human and the divine dispositional properties of the incarnate Logos are single-track. In that case, of the three problems of the bearer questions mentioned in section I, a single-track disposition view can be said to provide us with an excellent conceptual resource to show that the human and the divine dispositional properties can be linked to two independent bearers in Christ. If there are two persons in the incarnate Christ, then for any given human dispositional property, it will be the case that the property in question given an appropriate stimulus condition leads to its corresponding manifestation. Similarly, for any given divine dispositional property, it will be the case that the property in question given an appropriate stimulus condition results in its corresponding manifestation. So a proponent of a "two persons view" in one incarnate Christ can easily resolve the problem of the bearer question. This is because each independent person in the incarnate Christ, namely the divine person and the human person bears the corresponding dispositional properties. So the problem of ascribing incompatible properties to a single Christ would not arise in the two persons in Christ view. But this victory comes with a high price. This is because, the two persons in the incarnate Christ view is a Nestorianism heresy and hence, it violates CD. So a defender of Orthodox Christology cannot endorse this view while at the same time defending $(1)-(4)$, which make up CD. 
How does a single-track view fair with the hard problem of the bearer question? At the heart of the hard problem of the bearer question lies whether or not it is logically coherent to attribute incompatible dispositional properties to a single bearer. Notice that the sense in which we talk about a single bearer view under the hard problem of the bearer question is different compared to the sense suggested in the hybrid view. In the hybrid view, the notion of a single bearer is understood within the framework of ontological unity that characterizes the Logos's relation to Jesus of Nazareth. As we shall see, the notion of a single bearer makes a lot more sense within the framework of the hybrid view than it does within the framework of a single bearer view, which characterizes the hard problem of the bearer problem. But in the context of the hard problem of the bearer question, if the two dispositional properties of the incarnate logos are single track, then for any given human dispositional property, it will be the case that the property in question given an appropriate stimulus condition results in its corresponding manifestation. Similarly for any given divine dispositional property, it will be the case that the property in question given an appropriate stimulus condition results in its corresponding manifestation.

But the problem we face here turns out to be analogous to the issue of the logical coherence of attributing incompatible predicates to a single bearer. That is, the problem will be making sense of the coherence of attributing the manifestation of incompatible dispositional properties to a single bearer. Probably some of the same solutions proposed by philosophers such as Timothy Pawl to the logical incoherence problem might be said to help us here in resolving the hard problem of the bearer question in relation to a single-track disposition view. For now, I do not explore what that possibility might look like albeit I remain skeptical of how far success can be obtained in that regard. One reason for my skepticism has do with the fact that given a single-track disposition as it relates to a single bearer, it is not clear what principled criteria governs individual stimulus conditions and their corresponding individual manifestations. This makes it hard, inter alia, to see any attractive advantage of a single-track disposition to tackle the hard problem of the bearer question.

On the other hand, if it is seen from the standpoint of the hardest problem of the bearer question, a single-track disposition simply falls apart before it even gets off the ground. To see this, note that the hardest problem is said to be the hardest due to multi-faceted ontological issues it brings up. Here our interest is not only in figuring out how the two dispositional properties of the incarnate Logos co-exist in a single bearer but also the notion of a single bearer understood within a deeper ontological unity. That is precisely what the notion of "a single bearer-two bearers" scenario tries to capture. So the hybrid view 
which tries to resolve the hardest problem of the bearer question does not accommodate a single track disposition view.

Notice that my hitherto analysis of a single-track disposition in relation to the three problems of the bearer question took it for granted that there are single-track dispositions. But in light of our discussion of the metaphysics of dispositions in the first part of this section (A), the alleged single-track dispositions are not single track after all. Recall, for example, the qualitative diversity and the quantitative diversity problems. In the former case, the stimulus conditions responsible for various manifestation of dispositions can take qualitatively different forms whereas in the latter case, the stimulus conditions themselves come in various degrees. Because of these and similar other related problems, the very existence of the so-called single-track dispositions is entirely rejected. What should we do then? Of course, the answer is we should embrace multi-track dispositions.

\subsection{Reciprocal Partnership}

The great advantage of MDMI is that it does not require us to repeat any of the misgivings pointed out with respect to the single-track dispositions. According to MDMI, all of the divine dispositional properties that the Logos had in His pre-incarnate state did not have to be divested when He became incarnate. This is what (i) assumes as stated earlier. The Logos also experienced genuine humanity at the incarnation. This is what (ii) assumes as stated earlier. Now the issue is to show the unity between (i) and (ii). One way MDMI proposes to tackle the issue of unity is by introducing the notion of reciprocal partnership between the human and the divine dispositional properties. In this case, dispositional properties would manifest themselves differently with different reciprocal partners. So for any given human dispositional property and for any given divine dispositional property, it is always the case that there is mutual cooperation between them. Taken this way, the human and the divine dispositional properties of the incarnate Logos have multiple reciprocal partners. That means that negative interfering factors such as absences, preventers, antidotes, blockers, inhibitors, etc., will no longer be taken as stopping a certain disposition from being manifested. This is because such things themselves are dispositions manifesting themselves with various reciprocal partners.

For example, the dispositional properties that the Logos did manifest prior to His incarnation, such as omniscience, omnipotence, omnipresence and others have always been manifesting in His post-incarnate state as well. The only difference is that the manifestations have been happening in the multi-faceted ways or directions. For example, contrary to how the Kenosis theories portray 
it, when Christ said that He did not know when the end of the age would be, that did not show a lack of omniscience on His part at all. If Christ's claim here is taken to mean that He forfeited His omniscience. Rather what was happening there was that a different sort of manifestation was manifesting. In other words, the stimulus condition (Christ's humanity) in this case was responsible for bringing about the manifestation of Christ's claim of ignorance. Here one could say that the phrase 'Christ's claim of ignorance' sounds a lot like a kenotic or kryptic view. This is because kenotic theorists could also say a similar thing along the same lines. For example, they could say that the inability of a human nature implies why Christ was not able to manifest omniscience. ${ }^{9}$

But if we examine this matter within the context of MDMI on the one hand and the kenotic or kryptic models on the other, we get radically different results. For example, kenotic and kryptic theories tend to be compatible with the "stimulus-response relation" that I talked about and rejected. Again these theories do not embrace the sort of dynamic interaction which is assumed to be inherently present in the incarnate Logos's divine and human dispositional properties. There is no indication, as far as I can tell, that these theories locate the two dispositional properties of the incarnate Logos within the framework of multi-track dispositions. These differences are no small matter, although I cannot take up this discussion here. So I do not think that there is any good reason to lump MDMI with the kenotic or kryptic model. So if Christ's humanity is taken as an interfering factor in what the Logos would otherwise be capable of doing (in this case know the end of the age), our conclusion should not be that the Logos somehow divested Himself of His omniscience. Rather a different sort of disposition is being manifested in the opposite direction with a different reciprocal partner(s). Nor did Christ have to hide, say His omniscience, as kryptic theorists claim either. What seems to be the case here isn't the issue of hiding but rather it is the case of the manifestation of dispositions linked up with a different kind of reciprocal dispositional partners. MDMI does not leave any room for passive existence of any of the dispositional properties of the incarnate Logos.

So it is central to a proponent of MDMI to understand dispositions as being always in the state of manifesting themselves in multiple directions and ways. In light of this, in whatever the incarnate Logos does, He is always manifesting dispositional properties. This means that the incarnate Logos did not have to forfeit Himself of anything He necessarily has as a divine being. So given MDMI, the incarnate Christ retained His divine and human dispositional properties without sacrificing one at the expense of the other. This view, if true, not only best accommodates the spirit of $\mathrm{CD}$, but it also unquestionably

\footnotetext{
${ }^{9}$ I thank one of the referees for raising this objection.
} 
provides us with resources to make progress in tackling the hardest problem of the bearer question, as I will point out shortly. So when it seems to us that the incarnate Christ did not manifest His divine nature in certain situations, it was not because He somehow emptied Himself of His divine dispositional properties in a metaphysical sense. That is, quite literally lacking certain divine making properties. Rather given MDMI, the truth is that the incarnate Logos did not lose His divine dispositional properties, since the manifestings are taking place in the opposite direction. In fact, the very notion of 'emptying' or 'self-imposed limitations' makes no sense once we get to the heart of the MDMI presented here.

In light of this, the best way, to understand the Philippians 2:5 'kenosis', would be in its functional as opposed to metaphysical sense. Taken in its functional sense, all that the 'emptying' metaphor shows us is that the incarnate Logos made the scenario for various sorts of stimulus conditions to be possible by taking on a human form. Whatever the incarnate Logos does, it is the case that mutual manifestations of various dispositions linking up with reciprocal dispositional partners are operating in multifaceted ways. This is, in fact, precisely what seems to be happening in the Gospels where we see the incarnate Logos manifesting various sorts of the human dispositional properties and the divine dispositional properties. So rather than saying that the incarnate Christ does $X$ as a human and $Y$ as a divine, MDMI gives us an excellent conceptual framework to use the language of disposition manifestation. In doing so, it also shows us in what sense we should understand the incarnate Logos's different acts performed in different circumstances. The key point here is to realize that different stimulus conditions result in the manifestation of different dispositions. It seems then that the secrete behind all of the incarnate Logos's different manner of doing things may well have to do with the manifestation of various dispositions consistent with various stimulus conditions that generally lead to their manifestations.

In light of the hitherto discussion, MDMI points us in the right direction as to how we could go about tackling the hardest problem of the bearer question. First, it shows us how the two dispositional properties of the incarnate Logos can co-exist in perfect harmony in a single unified bearer. Second, it gives us conceptual resources to accommodate the notion of "a single bearer-two bearers" within the constraints placed by CD. So MDMI is more at home with the hybrid view defended in this essay that does justice to the core tenets of CD as stated in $(1)-(4)$.

In part III, I briefly show the contrast between MDMI and its rival, the Kenotic Model of Incarnation (Kenotic view, for short).

\section{The Kenosis Model of the Incarnation}


Unlike MDMI, the kenotic view resolves the hardest problem of the bearer question by claiming that while the human dispositional properties remain unchanged, the divine ones are divested while the Logos is incarnate. A kenotic Christology first emerged in the nineteenth century. Central biblical passages to the development of Kenosis theories, include: Philippians 2:5-11 and Mark 13:32. As we shall see, the Greek word 'kenosis' which is mentioned in Philippians 2:5 and translated as "emptying" or "emptied", plays a pivotal role in the way kenosis theories are often characterized. In the case of Mark 13:32, Jesus's confession of ignorance as to when the day or hour of the end times would be is taken to imply some sort of self-limitations on His part. But what sets the tone for all parties involved in this discussion concerns what to make of the word 'emptying' or 'emptied' in Philippians 2:5. Commenting on Philippians 2:5-8, biblical scholar, Dorothea Bertschmann (2018) remarks that the notion of self-emptying can be taken as contrasting alternatives to either grabbing or clutching Godlikeness. In this case, the sort of attitude Christ may have rejected could well be grabbing, clutching, or selfishly using Godlikeness (Bertschmann 2018, 237). But discussion amongst kenotic theorists regarding the doctrine of kenosis is often philosophical in nature. What precisely is the central thesis of the doctrine of kenosis? As Oliver Crisp puts it, "the notion of divine kenosis...is the idea that somehow the Word of God empties himself of certain divine attributes in order to become incarnate" $(2007, x i)$.

Crisp's characterization of the kenosis doctrine shows us what allegedly must happen on the part of the Logos to ensure genuine humanity. In this case, the Logos is said to have emptied Himself of certain divine dispositional properties. Often the kenotic theorist's favorite properties in this case are: omnipotence, omniscience and omnipresence. It is also said that the Logos emptied Himself of such properties temporarily (see Morris 1989, 119; see also Hick 1993, chap. 6). To get a good picture of this view, it is also important to keep in mind that not all kenotic theorists speak in one language in the way they spell out the details involved in the Logos's emptying Himself of the sorts of dispositional properties mentioned above.

For example, a notable nineteenth century theologian, Gottfried Thomasius argued that the Logos had to forfeit certain properties (e.g., omniscience), to ensure genuine humanity. However, Thomasius also argued that at no point, the Logos divested Himself of His deity (1965, 46-56; see also Feenstra 1989, 129-133). Other kenotic theorists think that kenosis resulted not only in the Logos's loss of the eternal self-consciousness but also marks the occasion whereby the Logos became a human soul. Still others think that even if the Logos did not lose divinity, kenosis perhaps changed the Logos's mode of being (existence) permanently. Yet again others say that the Logos might have lived a 
double life, that is, acting as a sustainer of the universe while at the same time being subject to limitations imposed on Him by His humanity (see Moreland and Craig 2003, 604-605).

The hitherto characterization as briefly summarized above could be taken as a strong version of the kenosis doctrine. This is because, the theories in one way or another require the Logos to divest Himself of certain dispositional properties in order to assume a complete human nature. In this case, the kenotic view stands in sharp contrast with the hybrid view defended in sections I and II of this essay. On kenotic view, it seems like the bearer of divine dispositional properties gives way to the bearer of the human dispositional properties. The balance in this case is tipped in favor of magnifying the humanity of the incarnate Logos. But MDMI in this case does a better job than its rival the kenotic view in terms of doing justice for the ontological status of the person of the incarnate Logos. It does this by allowing the human and the divine dispositional properties of the incarnate Logos to co-exist in a single bearer.

But recently a lively discussion has resurfaced in the literature which, in my view, restructures the kenosis doctrine in such a way that does not require the Logos to divest Himself of any of His dispositional properties. In this case, the doctrine of krypsis, or concealment takes center stage. For example, in his book A Kryptic Model of the Incarnation, Andrew Ter Ern Loke (2014) argues that during the incarnation, the Logos did not divest Himself of certain supernatural attributes; rather these properties were hidden. Loke develops the details for this view within the framework of what he calls, the Divine Preconscious Model (DPM). Details aside, central to Loke's DPM is the notion that at the incarnation, the Logos's dispositional properties (e.g., omniscience, omnipotence, and omnipresence) were hidden in the Logos's divine preconscious state. In this case, a human nature was assumed which also is said to include a human preconscious. The key to Loke's kryptic model is that no divine dispositional properties, as I call them, had to be lost or divested to make room for incarnation. So unlike the mainstream kenosis doctrine, Loke's version of the kryptic model of the incarnation can be taken as a weaker form of the general kenosis doctrine.

As should be expected, the literature is full of interesting responses, counterresponses and general criticisms of both the strong and the weak versions of the kenosis doctrine (see Crisp 2007, chap. 5 and Hick 1993, chap. 6). Morris introduced his famous and much discussed 'two minds' view of the incarnation as an alternative to kenosis theory (see Morris 1989, 110-127). But Morris's own view was criticized on grounds that it could open a door for Nestorianism (see Moreland and Craig 2003, 612 and Hick 1993, 58-76).

Compared to the kryptic model of the incarnation, again I believe that MDMI stands better equipped to give us a dynamic theologically and philosophically 
more informative analysis as to how the two dispositional properties of the incarnate Logos co-exist in a single bearer. MDMI does a better job in explaining what form the manifestation of the two dispositional properties of the incarnate Logos take. I find the kryptic view trading on a lot of obscure notions of hidden dispositional properties of the incarnate Logos. I do not think that we have any secure understanding as to how the incarnate Logos hides certain divine dispositional properties (cf. Arcadi 2016, 459-463). Let alone in the case of the incarnate Logos, even in our own case, we have an extremely impoverished grasp of how the mind-body interaction works. By contrast, MDMI provides us with a straightforward analysis of why and how both the dispositional properties of the incarnate Logos are kept intact.

Taken this way, I also do not see how the kenosis doctrine (strong and weak) can be said to do justice to CD (cf. Moreland and Craig, 2003, 605). I say this because kenosis theorists attempting to explain CD seem to involve interpretive revisions to $\mathrm{CD}$. Such revisions precisely come in forms that I have extensively argued against in this essay. Here I raise three of them. First, the kenosis theories seem to be guilty of what I called in part II, the humanity favoring problem. In this case, such theories fail to resolve the hardest problem of the bearer question. Given kenotic theories only the human bearer of the dispositional properties is magnified. But why leave out the divine bearer of dispositional properties? That means that these theories fail to do justice to the notion of "a single bearer-two bearers" explained and defended in part II.

Second, the kenosis theories suffer from attempting to have one's cake and eat it too. What I mean by this is that most (if not all) of the pro-Chalcedonian kenosis theorists do not want to allow the Logos's divinity to be compromised (see Evans 2002). Yet at the same time, they also cannot help but require the Logos to divest some of His divine dispositional properties such as omniscience and omnipresence. If so, how can they have it both ways? The answer often given for this is that the sort of dispositional properties said to have been divested by the Logos are not essential. But the sort of interpretation kenotic theorists give to dispositional properties such as omniscience and omnipresence remains to be highly controversial (see Plantinga 1998; Beilby and Eddy 2001). Although unlike the mainstream kenosis theory, the kryptic model of the incarnation recognizes that the Logos did not divest any of His divine properties, the very notion of such properties get portrayed as being hidden temporarily to leave room for the human nature slips back just like its cousin (i.e., kenosis theory) into the humanity favoring problem. So the kryptic model also fails to resolve the hardest problem of the bearer question. Hence, the kryptic model of the incarnation cannot avoid violating CD. 
Third, for all the reasons stated in sections I and II, kenosis theories (strong or weak versions), cannot avoid a revisionist reading into the Chalcedonian statement. Hence, they inevitably suffer from the problem of over-emphasizing the Logos's divinity over His humanity or over-emphasizing His humanity over His divinity. But the theory we need in order to be able to capture the heart of the Chalcedonian statement is one that does not attempt to introduce any revisionist readings into the Chalcedonian statement. In this case, MDMI does a good job as I argued. We need a theory that attempts to capture or at least points us in a promising conceptual direction in showing us how to think about CD without thereby violating the ontological status of the person of the incarnate Logos.

\section{Further Questions and Conclusion}

In this final section, my aim is to raise metaphysical questions that emerge from the bearer question for future research considerations.

Back to the hardest problem of the bearer question. Consider a red apple sitting on a kitchen table. Here, at least, two things can be singled out, namely, an apple, which is said to be an object and the redness of an apple, which is said to be a property. Here terms such as 'object' and 'property' can also be used interchangeably with related traditional Aristotelian terms such as, 'substance' (ousia) and 'attribute' (Loux 1978). A substance is a property bearer whereas a property is the way a substance is (see Heil 2012, chap. 2). To say that a property is the way a substance is, is to say that a property characterizes a substance as being a certain way. For example, the redness of a particular apple characterizes an apple as being red. In this case, the sort of relation that is said to exist between an apple (substance) and its redness (attribute) consists in the latter standing to the former in an exemplification or instantiation relation. A substance exemplifies a property and a property in turn gets exemplified by a substance. It is also the case that an apple and its redness belong to two distinct ontological categories. That is, the category of substance is not the same as the category of property. By 'category' it is meant that the general kinds under which things fall.

From an existential standpoint, properties ontologically depend on their bearers but the converse is not the case. Or in typical Aristotelian style, a property is said to be predicated of a substance but a substance is not said to be predicated of a property. So ontologically speaking, a substance is more fundamental in that it provides a metaphysical ground for the existential status of properties (see Ackrill 1963). In light of this, the question we should ask is this: does the Logos somehow stand to certain divine disposition making 
properties in the manner an apple stands to redness or redness stands to an apple?

More specifically, the bearer question gets more complicated in the following way. To see this, I turn to Aristotle's Categories (1963). There Aristotle introduces a distinction between a primary substance, or as some philosophers call it, 'individual substance' (see Lowe 2015, 70-72) or a concrete familiar object (Loux and Crisp 2017, Chap. 1) such as 'this Plato' and a secondary substance or 'substantial kind', such as 'human' (Lowe 2015, 71). Human is the kind to which concrete familiar objects belong. In Aristotle's ontology 'human' is a kind-term which fixes the essence of a primary substance. That is, a particular Plato is said to be a human being not because Plato is white but because Plato belongs to a kind 'human'. Plato's whiteness is an accidental property. A property $P$, is said to be accidental for a person $S$, if $S$ can lose $P$ thereby without ceasing to exist. By contrast, a property $P$, is said to be essential for a person, $S$, if $S$ cannot continue to exist without $P$. For example, if Plato loses 'humanness', then there would be no chance for Plato to exist. So 'humanness' is an essential property for Plato. Understood this way, 'humanness' is a kind universal.

Does the incarnate Logos have its divinity by belonging to a kind-divine? And does the incarnate Logos have its humanity by belonging to a kindhuman? If our answer for each of these questions is affirmative, then how can we escape the sort of problems associated with the well-known Euthyphro dilemma? Moreover, are the kind-divine and the kind-human universals? By 'universals', I mean properties that can be instantiated in multiple spatiotemporal domain at once. The sense in which I used the notion of 'property' as discussed above in relation to apple (i.e., redness) is different compared to kind universal. Neo-Aristotelian philosophers draw a distinction between two kinds of universals, namely property universals such as a particular redness of an apple and a kind universal such as humanness (Galluzzo 2015, Chap. 4).

Consider the kind-human, in relation to the embodied Logos and the rest of us humans. In what sense can the embodied Logos be said to share humanity with the rest of us? Is it by standing in a certain relation to the kind universal 'humanity' just like us or is there a different mode of instantiation of humanity that is unique to the embodied Logos?

Suppose one rejects universals. In that case, one might embrace properties as particulars; that is, rather than assuming properties as being multiply exemplifiable entities, one takes them to be exemplifiable only by a particular object at a particular time and space. For example, John exemplifies a property of being human. And similarly, Mark exemplifies a property of being human. But there is no universal 'humanity' of which John's exemplifying a property of being human is said to be a token of. Similarly, Mark exemplifying a property 
of being human, is not a token instantiation of the universal 'humanity'. John and Mark each exemplifies their own individual property of being human. On this view, there is no type (i.e. universal) of which individual, distinct tokens can be said to be instances of. John's property of being a human and Mark's property of being a human share nothing in common. However, in all other aspects, they can be said to share qualitatively similar properties. Taken this way, the Logos's property of being human is individually distinct from Marks property of being human. If so, is such a characterization theologically sound? Does it reflect CD's conception of the Logos's humanity?

In this paper, I attempted to analyze what the Chalcedonian Definition amounts to by giving an extensive discussion of the bearer question. In this case, I used my discussion of the bearer question to lay a ground for proposing the Multi-Track Disposition Model of the Incarnation. I have tried to show why this model provides us with better conceptual resources compared to the kenosis model in dealing with questions that arise as a result of the two natures of Christ in one person. Finally I listed further metaphysical questions that emerge from the bearer question which add further layers to the complexity that besets the bearer question. In light of all such observations, I conclude that with all that is being said and done, a conclusive answer to the bearer question still proves to be elusive. ${ }^{10}$

\section{Bibliography}

Ackrill, John. L. 1963. Aristotle's Categories and De Interpretatione. Oxford: Clarendon Press.

Arcadi, James. M. 2018. "Recent developments in analytic Christology". Philosophy Compass, 13:e12480: 1-12. https://doi.org/10.1111/phc3.12480.

Beilby, James. K and Eddy, Paul. R. (eds). 2001. Divine Foreknowledge. Downers Grove, IL: IVP.

Bertschmann, D. 2018. "Is There a Kenosis in This Text? Reading Phil. 3:2-11 in light of the Christ Hymn". Journal of Biblical Literature, 137,1: 235-254. https://doi.org/10.1353/jbl.2018.0014.

Bird, Alexander. 2007. Nature's Metaphysics: Laws and Properties. Oxford: Oxford University Press. https://doi.org/10.1093/acprof:oso/9780199227013.001.0001.

10 Acknowledgements: I presented this paper at the Society of Christian Philosophers Conference, Biola University (2017) and at the Dinner \& Dialogue Group at Redeemer Church, La Mirada (2018). I thank the participants for their feedback. I also thank Greg Ganssle, Greg Stump, Kyle Strobel and Matthew Owen for stimulating discussions. Finally, I thank anonymous referees for excellent feedback. 
Bird, Alexander. 2013. "Limitations of Power". In Powers and Capacities in Philosophy: The New Aristotelianism, edited by Ruth Groff and John Greco, 2930. New York: Routledge. https://doi.org/10.4324/9780203075609-2.

Chalmers, David J. 1996. The Conscious Mind: In Search of a Fundamental Theory. Oxford: Oxford University Press.

Chalmers, David J. 2010. The Character of Consciousness. Oxford: Oxford University Press. https://doi.org/10.1093/acprof:oso/9780195311105.001.0001.

Coakley, Sarah. 2002. "What Does Chalcedon Solve and What Does it Not? Some Reflections on the Status and Meaning of the Chalcedonian 'Definition.'” In The Incarnation: An Interdisciplinary Symposium on the Incarnation of the Son of God, edited by Stephen T. Davis, Daniel Kendall SJ and Gerald O'Collins SJ, 143-164. Oxford: Oxford University Press. https://doi.org/10.1093/0199248451.003.0007.

Crisp, Oliver D. 2007. Divinity and Humanity: The Incarnation Reconsidered. Cambridge: Cambridge University Press. https://doi.org/10.1017/CBO9780511805332.

Crisp, Oliver D. 2016. The Word Enfleshed: Exploring the Person and Work of Christ. Grand Rapids, MI: Baker Academic.

Feenstra, Ronald. 1989. "Reconsidering Kenotic Christology". In Trinity, Incarnation, and Atonement, edited by Ronald Feenstra and Cornelius Plantinga Jr., 128-152. Indiana: University of Notre Dame Press.

Evans, Stephen C. 2002. "The Self-Emptying of Love: Some Thoughts on Kenotic Christology". In The Incarnation: An Interdisciplinary Symposium on the Incarnation of the Son of God, edited by Stephen T. Davis, Daniel Kendall SJ and Gerald O'Collins SJ, 246-72. Oxford: Oxford University Press. https://doi.org/10.1093/0199248451.003.0011.

Galluzzo, Gabriele and Loux, Michael. J. (eds). 2015. The Problem of Universals in Contemporary Philosophy. Cambridge: Cambridge University Press.

Guta, Mihretu P. 2011. "Frank Jackson's Location Problem and Argument from the Self." Philosophia Christi, 13, 1:35-58.

Guta, Mihretu P. 2016. "Looking into Objects, Dispositions and the Lockean Person-Making Properties". Appraisal: The Journal of the British Personalist Forum, 11, 1: 4-11.

Heil, John. 2005. “Dispositions". Synthese, 144, 3: 343-356. https://doi.org/10.1007/s11229-005-5864-3.

Heil, John. 2012. The Universe as We Find It. Oxford: Oxford University Press. https://doi.org/10.1093/acprof:oso/9780199596201.001.0001.

Hick, John. 1993. Disputed Questions. New Haven: Yale University Press.

Hick, John. 1993. The Metaphor of God Incarnate. Louisville: Westminster John Knox Press. 
Holland, Richard A. Jr. 2012. God, Time, and the Incarnation. Eugene, OR: Wipf \& Stock.

Kim, Jaegwon. 2006. Philosophy of Mind. Cambridge, MA: Westview.

Loke, Andrew. T. E. 2014. A Kryptic Model of the Incarnation. Farnham: Ashgate.

Loux, Michael. 1978. Substance and Attribute. Indiana: University of Notre Dame. https://doi.org/10.1007/978-94-009-9874-2.

Loux, Michael and Crisp, Thomas M. 2017. Metaphysics a Contemporary Introduction. New York: Routledge. https://doi.org/10.4324/9781315637242.

Lowe, E. J. 2009. More Kinds of Being. Oxford: Willey Blackwell.

Lowe, E.J. 2008. Personal agency: The Metaphysics of Mind and Action. Oxford: Oxford University

Press. https://doi.org/10.1093/acprof:oso/9780199217144.001.0001.

Marmodoro, Anna and Hill, Jonathan. 2008. "Modeling the Metaphysics of the Incarnation". Philosophy E Theology, 20,1-2: 99-128.

Martin, C.B. 1994. "Dispositions and Conditionals". The Philosophical Quarterly, 44, 174: 1-8. https://doi.org/10.2307/2220143.

Martin, C.B. 2008. The Mind in Nature. New York: Oxford University Press.

Merricks, Trenton. 2007. "The Word Made Flesh: Dualism, Physicalism and the Incarnation." In Persons: Human and Divine, edited by Peter Van Inwagen, \& Dean Zimmerman, 281-300. Oxford: Oxford Clarendon.

Moreland, J. P. and Craig, William. L. 2003. Philosophical Foundations for a Christian Worldview. Downers Grove, IL: IVP.

Morris, Thomas.1986. The Logic of God Incarnate. Wipf \& Stock Publishers.

Morris, Thomas.1989. "Metaphysics of God Incarnate". In Trinity, Incarnation, and Atonement, edited by Ronald Feenstra and Cornelius Plantinga Jr., 110127. Indiana: University of Notre Dame Press.

Mumford, Stephen. 2013. "The Power of Power." In Powers and Capacities in Philosophy: The New Aristotelianism, edited by Ruth Groff and John Greco, 925. New York: Routledge. https://doi.org/10.4324/9780203075609-1.

Mumford, Stephen.1998. Dispositions. Oxford: Oxford University Press.

Murphy, Nancey and Warren, Brown S. 2007. Do My Neurons Make Me Do It?: Philosophical and Neurobiological Perspectives on Moral Responsibility and Free Will. Oxford University Press. https://doi.org/10.1093/acprof:oso/9780199215393.001.0001.

Owen, Matthew. 2018. "Aristotelian Causation \& Neural Correlates of Consciousness", Topoi. Special issue on Mental Powers, edited by Matteo Grasso and Anna Marmodoro. https://doi.org/10.1007/s11245-018-9606-9.

Pawl, Timothy. 2016. In Defense of Conciliar Christology: A Philosophical Essay. Oxford: Oxford University Press. https://doi.org/10.1093/acprof:oso/9780198765929.001.0001. 
Pawl, Timothy. 2014. "A Solution to the Fundamental Philosophical Problem of Christology". Journal of Analytic Theology, 2: 61-85.

Pawl, Timothy. 2015. "Conciliar Christology and the Problem of Incompatible Predications". Scientia et Fides, 3,2: 85-106. https://doi.org/10.12775/SetF.2015.019.

Noll, M. A. 1997/2000. Turning Points. Grand Rapids, MI: Baker Academic.

Sanders, Fred. 2007. "Introduction to Christology: Chalcedonian Categories for the Gospel Narrative." In Jesus in Trinitarian Perspective: An Introductory Christology, edited by Fred Sanders and Klaus Issler, 1-41. Nashville: B \& H Academic.

Plantinga, Alvin. 1998. The Analytic Theist an Alvin Plantinga Reader, edited by James F. Sennett, 214-224. Grand Rapids: William B. Eerdmans Pub.

Senor, Thomas D. 2007. “The Incarnation". In The Routledge Companion to Philosophy of Religion, edited by Chad Meister and Paul Copan, 556-565. New York: Routledge.

Thomasius, Gottfried. 1965. Christ's Person and Work Part II: The person of the Mediator, pp. 46-56 of God and Incarnation, edited \& translated by Claude Welch. Oxford: Oxford University Press.

Vetter, Barbara. 2015. Potentiality: From Dispositions to Modality. Oxford University Press,

Vetter, Barbara. 2013. "Multi-Track Dispositions". The Philosophical Quarterly, 63,251: 230-252.

Webster, John. 2004. "Incarnation." In The Blackwell Companion to Modern Theology, edited by Gareth Jones, 204-226. Oxford, Blackwell. https://doi.org/10.1002/9780470996768.ch13.

Published Online: January 19, 2019 